\title{
ФОНОННІ СПЕКТРИ ТА ЕЛЕКТРОН-ФОНОННА ВЗАЄМОДІЯ У СКЛАДНІЙ ЦИЛІНДРИЧНІЙ НАПІВПРОВІДНИКОВІЙ НАНОТРУБЦІ
}

\author{
О.М. МАХАНЕЦЬ, Н.Р. ЦЮПАК, В.І. ГУЦУЛ \\ Чернівецький національний університет ім. Ю.Федьковича \\ (Вул. Кочюбинсъкого, 2, Чернівиі 58012; e-mail: ktf@ chnu. edu. иа)
}

УДК 538.958, 538.9759

(C) 2012

\begin{abstract}
У моделі ефективних мас для електрона та діелектричного континууму для фононів розвинуто теорію електрон-фононної взаємодії у складній циліндричній напівпровідниковій нанотрубці. Одержано аналітичні вирази для гамільтоніанів взаємодії електрона з обмеженими та інтерфейсними фононами у зображенні вторинного квантування за електронними і фононними змінними. Досліджено залежності фононних енергій та потенціалу поля поляризації інтерфейсних фононів від аксіального квазіімпульсу та геометричних параметрів складної нанотрубки на основі напівпровідників $\mathrm{GaAs}$ та $\mathrm{Al}_{0,4} \mathrm{Ga}_{0,6} \mathrm{As}$.
\end{abstract}

\section{1. Вступ}

Напівпровідникові квантові дроти вивчаються як теоретично, так і експериментально вже протягом 20 років. Удосконалення методів їх вирощування (молекулярно-променева, газофазова та металорганічна епітаксія) дало змогу формувати не лише окремі дротини, а й просторово точно упорядковані ансамблі квантових нанодротів з радіальною гетероструктурою $[1,2]$.

Така, перпендикулярна до осі квантового дроту гетероструктура, з одного боку, може локалізувати носії заряду у внутрішній дротині, зменшуючи поверхневе розсіювання [3], а з іншого, залежно від її геометричних параметрів, дозволяє цілеспрямовано змінювати спектральні параметри основних квазічастинок (електронів, екситонів, фононів) у наносистемі.

Унікальні властивості квазічастинок у таких системах дозволяють використовувати їх у ролі базових елементів тунельних нанодіодів, нанотранзисторів з високою рухливістю електронів, високоефективних світловипромінюючих приладів, фотоперетворю- вачів, наносенсорів для діагностики різних біологічних і хімічних з'єднань [4].

Одним із різновидів квантових дротів з радіальною гетероструктурою є напівпровідникові нанотрубки, які також інтенсивно досліджуються. Так, залежно від напівпровідникових матеріалів, що входять до складу гетероструктури, експериментаторами вже створено прості (з однією квантовою ямою для електрона) $[5,6]$ та складні (багатоямні) кількашарові [7, 8] нанотрубки.

Щодо простих квантових дротів та нанотрубок, то вони детально досліджувалися теоретично у роботах [9-11]. Авторами було побудовано теорію енергетичного спектра електронів, дірок, фононів та взаємодії цих квазічастинок між собою, яка досягла не тільки якісного, а й кількісного узгодження з експериментальними даними.

Теоретичні дослідження складних кількашарових напівпровідникових нанотрубок лише починаються. Зокрема, у роботі [12] авторами було побудовано теорію електронного і екситонного енергетичних спектрів та досліджено їх залежність від геометричних параметрів складної нанотрубки.

Наскільки нам відомо, послідовна теорія фононного спектра у таких системах поки що відсутня. То ж відсутня і теорія взаємодії електрона з фононами, як однією із дисипативних підсистем, яка, очевидно, впливатиме на випромінювальну чи поглинальну здатність нанотрубки.

Тому метою даної роботи є побудова теорії фононних спектрів та електрон-фононної взаємодії у складній циліндричній напівпровідниковій нанотрубці (рис.1). Як приклад будуть досліджені особливості основних характеристик фононного поля залежно від 
геометричних параметрів наносистеми на основі напівпровідників GaAs та $\mathrm{Al}_{0,4} \mathrm{Ga}_{0,6}$ As.

\section{2. Енергетичний спектр і хвильові функції електрона у складній циліндричній напівпровідниковій нанотрубці без врахування взаємодії з фононами}

У роботі досліджується наносистема, що є складною циліндричною напівпровідниковою нанотрубкою. Вона складається із квантового дроту (середовище "0"), тонкого напівпровідникового шару - бар'єра ("1") та нанотрубки (“2”) у зовнішньому середовищі (“3”) (рис. 1).

Оскільки сталі граток $\left(a_{0}, a_{1}\right)$ та діелектричні проникності складових наносистеми слабо відрізняються між собою, а самі розміри наносистеми такі, що $\rho_{0}, \Delta, h>a_{0}\left(a_{1}\right)$, то для розрахунку енергетичного спектра електрона можна використати наближення ефективних мас $(\mu)[13,14]$ та прямокутних потенціалів $(U)$. Отже, діелектричні проникності, ефективні маси та потенціальні енергії електрона вважаються відомими у всіх областях складної нанотрубки, і в циліндричній системі координат з віссю $O Z$ уздовж аксіальної осі наносистеми, визначаються так

$\varepsilon(\rho, \omega)=\left\{\begin{array}{l}\varepsilon_{0}(\omega) \\ \varepsilon_{1}(\omega)\end{array}, \quad \mu(\rho)=\left\{\begin{array}{l}\mu_{0} \\ \mu_{1}\end{array}\right.\right.$,

$U(\rho)=\left\{\begin{array}{l}0, \quad 0 \leq \rho \leq \rho_{0}, \quad \rho_{1} \leq \rho \leq \rho_{2} \\ U_{0}, \quad \rho_{0} \leq \rho \leq \rho_{1}, \quad \rho>\rho_{2}\end{array}\right.$

Гамільтоніан електрона без врахування взаємодії $з$ фононами має вигляд

$\hat{H}_{e}(\rho, \varphi, z)=-\frac{\hbar^{2}}{2 \mu(\rho)} \frac{\partial^{2}}{\partial z^{2}}+U(\rho)-$

$-\frac{\hbar^{2}}{2 \rho}\left[\frac{\partial}{\partial \rho}\left(\frac{\rho}{\mu(\rho)}\right) \frac{\partial}{\partial \rho}+\frac{1}{\rho} \frac{\partial^{2}}{\partial \varphi^{2}}\right]$.

Стаціонарне рівняння Шредінгера:

$\hat{H}_{e}(\rho, \varphi, z) \psi(\rho, \varphi, z)=E \psi(\rho, \varphi, z)$

розв'язується точно і хвильові функції отримуються у вигляді

$\Psi_{m k}(\mathbf{r})=\frac{1}{\sqrt{2 \pi L}} R_{m k}^{(p)}(\rho) e^{i k z} e^{i m \varphi}, \quad p=0,1,2,3$

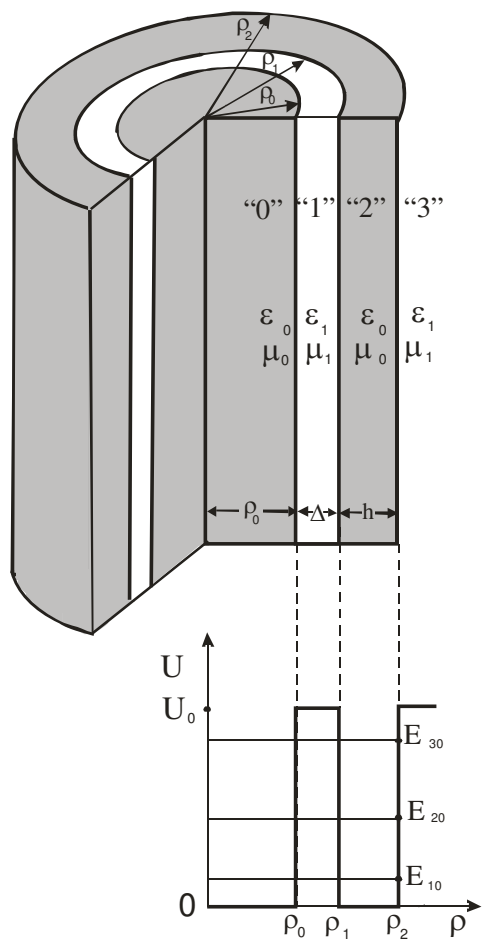

Рис. 1. Геометрична та енергетична схеми складної циліндричної нанотрубки

з радіальними функціями

$R_{m k}^{(p)}(\rho)=$

$=\left\{\begin{array}{lc}A_{m}^{(0)} J_{m}\left(\chi_{0} \rho\right), & 0 \leq \rho \leq \rho_{0}, \\ A_{m}^{(1)} I_{m}\left(\chi_{1} \rho\right)+B_{m}^{(1)} K_{m}\left(\chi_{1} \rho\right), & \rho_{0} \leq \rho \leq \rho_{1} \\ A_{m}^{(2)} J_{m}\left(\chi_{0} \rho\right)+B_{m}^{(2)} N_{m}\left(\chi_{0} \rho\right), & \rho_{1} \leq \rho \leq \rho_{2} \\ B_{m}^{(3)} K_{m}\left(\chi_{1} \rho\right), & \rho \geq \rho_{2}\end{array}\right.$

Тут

$\chi_{0}=\sqrt{2 \mu_{0} E / \hbar^{2}-k^{2}}, \quad \chi_{1}=\sqrt{2 \mu_{1}\left(U_{0}-E\right) / \hbar^{2}+k^{2}}$,

$k$ - аксіальний квазіімпульс; $m=0, \pm 1, \pm 2, \ldots$ - магнітне квантове число; $L$ - величина ефективної області руху електрона вздовж аксіальної осі нанотрубки; $J_{m}, N_{m}$ - функції Бесселя та Неймана цілого порядку відповідно; $I_{m}, K_{m}$ - модифіковані функції Бесселя [15].

Умови неперервності хвильових функцій та відповідних потоків густин ймовірностей на всіх трьох ме- 
жах наносистеми $\left(\rho=\rho_{0}, \rho_{1}, \rho_{2}\right)$ :

$$
\left\{\begin{array}{l}
R_{m k}^{(p)}\left(\rho_{p}\right)=R_{m k}^{(p+1)}\left(\rho_{p}\right), \quad(p=0,1,2) \\
\left.\frac{1}{\mu_{p}} \frac{\partial R_{m k}^{(p)}(\rho)}{\partial \rho}\right|_{\rho=\rho_{p}}=\left.\frac{1}{\mu_{p+1}} \frac{\partial R_{m k}^{(p+1)}(\rho)}{\partial \rho}\right|_{\rho=\rho_{p}},
\end{array}\right.
$$

разом з умовою нормування

$$
\int_{0}^{\infty}\left|R_{m k}(\rho)\right|^{2} \rho d \rho=1
$$

визначають усі невідомі коефіцієнти $A_{m}^{(p)}, B_{m}^{(p)}(p=$ $0,1,2,3)$, що входять у $(5)$, а отже, і аналітичні вирази для хвильових функцій $\psi_{n_{\rho} m k}(\mathbf{r})$ та дисперсійне рівняння, розв'язки якого нумеруються радіальними квантовими числами $n_{\rho}=1,2, \ldots$ і визначають спектр енергій $\left(E_{n_{\rho} m}(k)\right)$ електрона.

\section{3. Взаємодія електрона з обмеженими та інтерфейсними фононами у складній циліндричній нанотрубці}

У моделі діелектричного континууму поле поляризації складної нанотрубки визначається системою рівнянь Максвела для середовищ:

$$
\left\{\begin{array}{l}
\mathbf{D}=\varepsilon(\rho, \omega) \mathbf{E}=\mathbf{E}+4 \pi \mathbf{P} \\
\mathbf{E}=-\nabla \Phi \\
\nabla \mathbf{D}=0
\end{array}\right.
$$

де $\vec{D}$ - вектор індукцї електричного поля, $\Phi$ - потенціал поля поляризації, $\vec{P}$ - вектор поляризації.

Із системи (9) одержується рівняння

$\boldsymbol{\nabla}(\varepsilon(\rho, \omega) \nabla \Phi(\mathbf{r}))=0$,

яке має два можливих розв'язки, що зумовлюють існування двох типів фононного поля $[16,17]$ :

а) поляризаційне поле обмежених фононів, яке визначається умовами

$\varepsilon_{p}(\rho, \omega)=0, \quad \Delta \Phi_{L_{p}}(\mathbf{r}) \neq 0, \quad p=0,1,2,3 ;$

б) поляризаційне поле інтерфейсних фононів, яке визначається умовами

$\varepsilon_{p}(\rho, \omega) \neq 0, \quad \Delta \Phi_{I_{p}}(\mathbf{r})=0, \quad p=0,1,2,3$.

Спектр енергій усіх гілок фононів і відповідні їм потенціали у нанотрубці знаходяться так.

\section{1. Обмежені фонони}

Діелектрична проникність кожного із напівпровідникових шарів складної нанотрубки вважається відомою функцією частоти

$\varepsilon_{p}(\omega)=\varepsilon_{p \infty} \frac{\omega^{2}-\omega_{L_{p}}^{2}}{\omega^{2}-\omega_{T_{p}}^{2}}, \quad p=0,1$,

де $\varepsilon_{p \propto}, \omega_{L p}, \omega_{T p}-$ високочастотні діелектричні проникності та частоти поздовжних і поперечних фононів у відповідних масивних кристалах. Із (11) та (13) видно, що спектр власних енергій обмежених фононів циліндричної нанотрубки збігається з частотами поздовжних оптичних фононів відповідних масивних кристалів, з яких утворена нанотрубка:

$\Omega_{L_{p}}=\hbar \omega_{L_{p}}$.

Далі знаходиться потенціал поля поляризації $\Phi_{L}(\mathbf{r})$ і відповідна складова вектора зміщення $\mathbf{u}_{L}$, що зумовлені обмеженими оптичними фононами. Для цього, враховуючи циліндричну симетрію системи, складові потенціалу $\Phi_{L}(\mathbf{r})$ шукаються у вигляді розкладу за повною системою циліндрично-симетричних функцій у кожній із областей наносистеми:

$$
\begin{aligned}
& \left.\Phi_{L_{0}}(\mathbf{r})\right|_{\rho \leq \rho_{0}}=\sum_{m k_{0} q} \Phi_{m q}\left(k_{0}\right) B_{k_{0}} J_{m}\left(k_{0} \rho\right) e^{i q z} e^{i m \varphi}, \\
& \left.\Phi_{L_{p}}(\mathbf{r})\right|_{\rho_{p-1} \leq \rho \leq \rho_{p}}=
\end{aligned}
$$

$=\sum_{m k_{p} q} \Phi_{m q}\left(k_{p}\right)\left(B_{k_{p}} J_{m}\left(k_{p} \rho\right)+A_{k_{p}} N_{m}\left(k_{p} \rho\right)\right) e^{i q z} e^{i m \varphi}$,

$(p=1,2)$,

$\left.\Phi_{L_{3}}(\mathbf{r})\right|_{\rho \geq \rho_{2}}=\sum_{m k_{3} q} \Phi_{m q}\left(k_{3}\right) A_{k_{3}} N_{m}\left(k_{3} \rho\right) e^{i q z} e^{i m \varphi}$.

Тут $J_{m}\left(k_{p} \rho\right), N_{m}\left(k_{p} \rho\right)$ - функції Бесселя та Неймана цілого порядку відповідно, $q$ - аксіальний квазіімпульс. Усі невідомі коефіцієнти $A_{k_{p}}, B_{k_{p}}, \Phi_{m q}\left(k_{p}\right)$ та самі квазіхвильові числа $k_{p}$ знаходяться з умов зникнення потенціалів поляризації на межах між середовищами наносистеми та з умов ортонормованості повної системи функцій, на яких здійснюється квантування цього фононного поля.

У результаті одержується гамільтоніан взаємодії електрона з полем поляризації $\widehat{\Phi}_{L}(\vec{r})$ у зображенні 
вторинного квантування за фононними, та в координатному за електронними змінними:

$$
\begin{aligned}
& \hat{H}_{e-L}(\rho, \varphi, z)=-e \hat{\Phi}_{L}(\mathbf{r})= \\
& =-\sqrt{\frac{2 e^{2} \Omega_{L_{0}}}{L}\left(\frac{1}{\varepsilon_{\infty 0}}-\frac{1}{\varepsilon_{00}}\right)} \sum_{m q} \frac{1}{\rho_{0} \sqrt{k_{0}^{2}+q^{2}}} \times \\
& \times\left.\frac{J_{m}\left(k_{0} \rho\right) e^{i q z} e^{i m \varphi}}{\left|J_{m+1}\left(k_{0} \rho_{0}\right)\right|}\left(\hat{b}_{m q k_{0}}+\hat{b}_{-m,-q k_{0}}^{+}\right)\right|_{\rho \leq \rho_{0}}- \\
& -\sum_{p=1}^{2} \sqrt{\frac{2 e^{2} \Omega_{L_{p}}}{L}\left(\frac{1}{\varepsilon_{\infty p}}-\frac{1}{\varepsilon_{0 p}}\right)} \frac{\pi}{2} \sum_{m q} \frac{k_{p}}{\sqrt{k_{p}^{2}+q^{2}}} \times \\
& \times\left[\frac{1}{N_{m}^{2}\left(k_{p} \rho_{p}\right)}-\frac{1}{N_{m}^{2}\left(k_{p} \rho_{p-1}\right)}\right]^{-1 / 2} \times \\
& \times\left[J_{m}\left(k_{p} \rho\right)-\frac{J_{m}\left(k_{p} \rho_{p-1}\right)}{N_{m}\left(k_{p} \rho_{p-1}\right)} N_{m}\left(k_{p} \rho\right)\right] \times \\
& \times\left. e^{i q z} e^{i m \varphi}\left(\hat{b}_{m q k_{p}}+\hat{b}_{-m,-q k_{p}}^{+}\right)\right|_{\rho_{p-1} \leq \rho \leq \rho_{p}}- \\
& -\sqrt{\frac{2 e^{2} \Omega_{L_{1}}}{L}\left(\frac{1}{\varepsilon_{\infty 1}}-\frac{1}{\varepsilon_{01}}\right)} \sum_{m q} \frac{1}{\rho_{2} \sqrt{k_{3}^{2}+q^{2}}} \times \\
& \times\left.\frac{N_{m}\left(k_{3} \rho\right) e^{i q z} e^{i m \varphi}}{\left|N_{m+1}\left(k_{3} \rho_{2}\right)\right|}\left(\hat{b}_{m q k_{3}}+\hat{b}_{-m,-q k_{3}}^{+}\right)\right|_{\rho \geq \rho_{2}} .
\end{aligned}
$$

Тут оператори вторинного квантування $\hat{b}_{m q k_{p}}$ та $\hat{b}_{m q k_{p}}^{+}$задовольняють бозонні комутаційні співвідношення

$$
\left[\hat{b}_{m q k_{p}}, \hat{b}_{m^{\prime} q^{\prime} k_{p}^{\prime}}^{+}\right]=\delta_{m m^{\prime}} \delta_{k_{p} k_{p}^{\prime}} \delta_{q q^{\prime}}
$$

\section{2. Інтерфейсні бонони}

Поляризаційне поле інтерфейсних фононів визначається рівняннями (12).

Функцію, яка задовольняє рівняння Лапласа (12), з урахуванням циліндричної симетрії нанотрубки, доцільно шукати у вигляді

$\Phi_{I}^{(p)}(\mathbf{r})=f_{m}^{(p)}(\rho) e^{i m \varphi} e^{i q z} \quad(p=0,1,2,3)$.

Підстановка (18) у (12) приводить до рівняння Бесселя для функції $f_{m}^{(p)}$ :

$$
\left(\frac{\partial^{2}}{\partial \rho^{2}}+\frac{1}{\rho} \frac{\partial}{\partial \rho}-\left(\frac{m^{2}}{\rho^{2}}+q^{2}\right)\right) f_{m}^{(p)}(\rho)=0,
$$

розв'язками якого у різних областях зміни $\rho$ є модифіковані функції Бесселя:

$$
f_{m q}^{(p)}(\rho)= \begin{cases}A_{0} I_{m}(q \rho), & \rho \leq \rho_{0}, \\ A_{1} I_{m}(q \rho)+B_{1} K_{m}(q \rho), & \rho_{0} \leq \rho \leq \rho_{1} \\ A_{2} I_{m}(q \rho)+B_{2} K_{m}(q \rho), & \rho_{1} \leq \rho \leq \rho_{2} \\ B_{3} K_{m}(q \rho), & \rho \geq \rho_{2}\end{cases}
$$

Потенціал поля поляризації інтерфейсних фононів $\Phi_{I}$, згідно із законами електродинаміки, повинен бути таким, щоб створені ним тангенціальна складова напруженості і нормальна складова індукції були неперервними на кожній із меж складної циліндричної нанотрубки:

$$
\begin{aligned}
& \mathbf{E}_{\tau_{p}}\left(\rho_{p}\right)=\mathbf{E}_{\tau_{p+1}}\left(\rho_{p}\right), \quad \mathbf{D}_{n_{p}}\left(\rho_{p}\right)=\mathbf{D}_{n_{p+1}} \rho_{p}, \\
& p=0,1,2 .
\end{aligned}
$$

Крайові умови (21) приводять до системи лінійних однорідних рівнянь відносно невідомих коефіцієнтів $A_{p}, B_{p} .3$ цієї системи отримується дисперсійне рівняння, розв'язки якого $\left(\omega_{m s}(q)\right)$ нумеруються квантовим числом $s$ і визначають енергетичний спектр інтерфейсних фононів системи:

$$
\Omega_{m s}(q)=\hbar \omega_{m s}(q)
$$

та самі коефіцієнти $A_{p}, B_{p}$. Через громіздкість дисперсійного рівняння та виразів для $A_{p}, B_{p}$, їхній явний вигляд не приводиться.

Отже, гамільтоніан взаємодії електрона з полем поляризації $\hat{\Phi}_{I}(\mathbf{r})$ у зображенні вторинного квантування за фононними, та в координатному за електронними змінними одержується у вигляді

$\hat{H}_{e-I}(\rho, \varphi, z)=-e \hat{\Phi}_{I}(\mathbf{r})=$

$=-\sum_{m q s} \Phi_{m q s}(\rho) e^{i q s} e^{i m \varphi}\left(\hat{b}_{m q s}+\hat{b}_{-m,-q s}^{+}\right)=$

$=-\sum_{m q s} \sqrt{\frac{\hbar e^{2}}{L y_{q s} \omega_{m s}(q)}} e^{i q z} e^{i m \varphi} \times$

$\times\left[\left.A_{0} I_{m}(q \rho)\right|_{\rho \leq \rho_{0}}+\left.B_{3} K_{m}(q \rho)\right|_{\rho \geq \rho_{2}}+\right.$

$\left.+\left.\sum_{p=1}^{2}\left[A_{p} I_{m}(q \rho)+B_{p} K_{m}(q \rho)\right]\right|_{\rho_{p-1} \leq \rho \leq \rho_{p}}\right] \times$

$\left.\times\left(\hat{b}_{m q s}+\hat{b}_{-m,-q s}^{+}\right)\right]$, 
де

$$
\begin{aligned}
& y_{q s}=\frac{1}{2}\left(\left.\frac{\left(\varepsilon_{00}-\varepsilon_{\infty 0}\right) \omega_{T 0}^{2}}{\left(\omega_{m s}^{2}(q)-\omega_{T 0}^{2}\right)^{2}} \rho_{0} f_{m}^{(0)}\left(\rho_{0}\right) \frac{\partial f_{m}^{(0)}(\rho)}{\partial \rho}\right|_{\rho_{0}}+\right. \\
& +\left.\frac{\left(\varepsilon_{01}-\varepsilon_{\infty 1}\right) \omega_{T 1}^{2}}{\left(\omega_{m s}^{2}(q)-\omega_{T 1}^{2}\right)^{2}} \rho_{2} f_{m}^{(3)}\left(\rho_{2}\right) \frac{\partial f_{m}^{(3)}(\rho)}{\partial \rho}\right|_{\rho_{2}}+ \\
& \left.+\left.\sum_{p=1}^{2} \frac{\left(\varepsilon_{0 p}-\varepsilon_{\infty p}\right) \omega_{T p}^{2}}{\left(\omega_{m s}^{2}(q)-\omega_{T p}^{2}\right)^{2}} \rho f_{m}^{(p)}(\rho) \frac{\partial f_{m}^{(p)}(\rho)}{\partial \rho}\right|_{\rho_{p-1}} ^{\rho_{p}}\right) .
\end{aligned}
$$

Перехід до зображення чисел заповнення за електронними змінними у гамільтоніанах (16) та (23) здійснюється згідно з загальною теорією на квантованих хвильових функціях:

$\hat{\Psi}_{n_{\rho} m k}(\mathbf{r})=\sum_{n_{\rho} m k} \hat{\Psi}_{n_{\rho} m k}(\mathbf{r}) \hat{a}_{n_{\rho} m k}$,

$\hat{\Psi}_{n_{\rho} m k}^{+}(\mathbf{r})=\sum_{n_{\rho} m k} \hat{\Psi}_{n_{\rho} m k}^{*}(\mathbf{r}) \hat{a}_{n_{\rho} m k}^{+}$,

де $\hat{a}_{n_{\rho} m k}, \hat{a}_{n_{\rho} m k}^{+}-$ферміївські оператори знищення та народження електронних станів, що описуються хвильовими функціями $\Psi_{n_{\rho} m k}(\mathbf{r})(4)$.

$\mathrm{y}$ результаті гамільтоніан електронів і електронфононної взаємодії у зображенні вторинного квантування за всіма змінними матиме вигляд

$\hat{H}=\int \Psi_{n_{\rho} m k}^{+}(\mathbf{r})\left(\hat{H}_{e}(\mathbf{r})+\hat{H}_{e-L}(\mathbf{r})+\right.$

$\left.+\hat{H}_{e-I}(\mathbf{r})\right) \Psi_{n_{\rho}^{\prime} m^{\prime} k}^{\prime}(\mathbf{r}) d^{3} \mathbf{r}=$

$=\hat{H}_{e}+\hat{H}_{e-L}+\hat{H}_{e-I}$.

Тут

$\hat{H}_{e}=\sum_{n_{\rho} m k} E_{n_{\rho} m}(k) \hat{a}_{n_{\rho} m k}^{+} \hat{a}_{n_{\rho} m k}$

- електронний гамільтоніан у зображенні своїх чисел заповнення,

$\hat{H}_{e-L}=\sum_{p=0}^{3} \sum_{k q k_{p}} \sum_{m m_{1}} \sum_{n_{\rho 1} n_{\rho 2}} F_{n_{\rho 1} m_{1} k}^{n_{\rho 2} m_{1}+m}\left(m, q, k_{p}\right) \times$

$\times \hat{a}_{n_{\rho 1} m_{1} k+q}^{+} \hat{a}_{n_{\rho 2} m_{1}+m k}\left(\hat{b}_{m q k_{p}}^{+}+\hat{b}_{-m-q k_{p}}\right)$

- гамільтоніан взаємодії електрона з обмеженими $L$ фононами, що містить функції зв'язку

$F_{n_{\rho 1} m_{1} k}^{n_{\rho 2} m_{1}+m}\left(m, q, k_{0}\right)=$

\section{4}

$$
\begin{aligned}
& =\sqrt{\frac{2 e^{2} \Omega_{L 0}}{L}\left(\frac{1}{\varepsilon_{\infty 0}}-\frac{1}{\varepsilon_{00}}\right)} \frac{1}{\rho_{0} \sqrt{k_{0}^{2}+q^{2}}} \frac{1}{\left|J_{m+1}\left(k_{0} \rho_{0}\right)\right|} \times \\
& \times \int_{0}^{\rho_{0}} R_{n_{\rho 1} m_{1} k+q}^{*}(\rho) R_{n_{\rho 2} m_{1}+m k}(\rho) J_{m}\left(k_{0} \rho\right) \rho d \rho, \\
& F_{n_{\rho 1} m_{1} k}^{n_{\rho 2} m_{1}+m}\left(m, q, k_{3}\right)= \\
& =\sqrt{\frac{2 e^{2} \Omega_{L 1}}{L}\left(\frac{1}{\varepsilon_{\infty 1}}-\frac{1}{\varepsilon_{01}}\right)} \frac{1}{\rho_{2} \sqrt{k_{3}^{2}+q^{2}}} \frac{1}{\left|N_{m+1}\left(k_{3} \rho_{0}\right)\right|} \times \\
& \times \int_{\rho_{2}}^{\infty} R_{n_{\rho 1} m_{1} k+q}^{*}(\rho) R_{n_{\rho 2} m_{1}+m k}(\rho) N_{m}\left(k_{3} \rho\right) \rho d \rho, \\
& F_{n_{\rho 1} m_{1} k}^{n_{\rho 2} m_{1}+m}\left(m, q, k_{p=1,2}\right)= \\
& =\sqrt{\frac{2 e^{2} \Omega_{L p}}{L}\left(\frac{1}{\varepsilon_{\infty p}}-\frac{1}{\varepsilon_{0 p}}\right)} \frac{\pi}{2} \frac{k_{p}}{\sqrt{k_{p}^{2}+q^{2}}} \times \\
& \times\left[\frac{1}{N_{m}^{2}\left(k_{p} \rho_{p}\right)}-\frac{1}{N_{m}^{2}\left(k_{p} \rho_{p-1}\right)}\right]^{-1 / 2} \times \\
& \times \int_{\rho_{p-1}}^{\rho_{p}} R_{n_{\rho 1} m_{1} k+q}^{*}(\rho) R_{n_{\rho 2} m_{1}+m k}(\rho) \times \\
& \times\left[J_{m}\left(k_{p} \rho\right)-\frac{J_{m}\left(k_{p} \rho_{p-1}\right)}{N_{m}\left(k_{p} \rho_{p-1}\right)} N_{m}\left(k_{p} \rho\right)\right] \rho d \rho .
\end{aligned}
$$

Гамільтоніан взаємодії електрона з інтерфейсними I-фононами

$\hat{H}_{e-I}=\sum_{k q s} \sum_{m m_{1}} \sum_{n_{\rho 1} n_{\rho 2}} F_{n_{\rho 1} m_{1} k}^{n_{\rho 2} m_{1}+m}(m, q, s) \times$

$$
\hat{a}_{n_{\rho 1} m_{1} k+q}^{+} \hat{a}_{n_{\rho 2} m_{1}+m k}\left(\hat{b}_{m q s}^{+}+\hat{b}_{-m-q s}\right)
$$

містить функції зв'язку

$F_{n_{\rho 1} m_{1} k}^{n_{\rho 2} m_{1}+m}(m, q, s)=$

$$
\begin{aligned}
& =\sqrt{\frac{e^{2} \Omega_{m s}(q)}{L y_{q s}}} \int_{0}^{\infty} R_{n_{\rho 1} m_{1} k+q}^{*}(\rho) R_{n_{\rho 2} m_{1}+m k}(\rho) \rho d \rho \times \\
& \times\left[I_{m}(q \rho)_{\rho \leq \rho_{0}}+\left.B_{3} K_{m}(q \rho)\right|_{\rho \geq \rho_{2}}+\right.
\end{aligned}
$$

ISSN 2071-0194. Укр. фіз. журн. 2012. T. 57, №10 

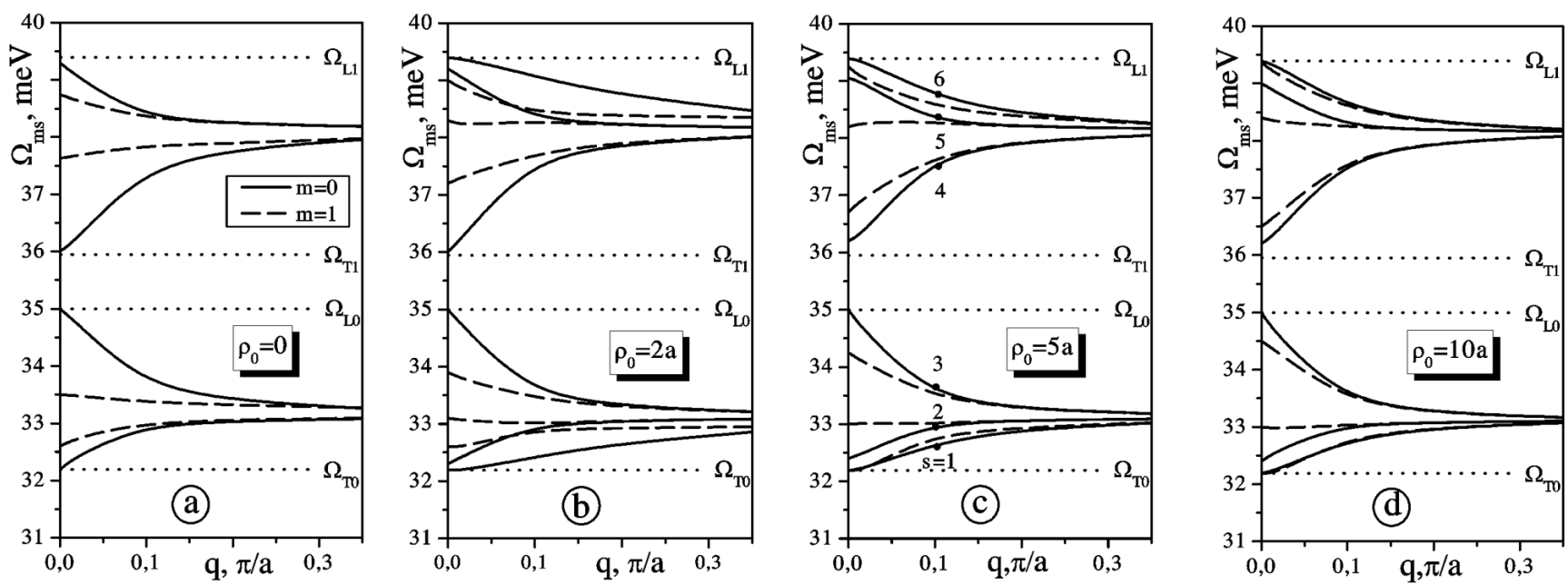

Рис. 2. Залежності енергій обмежених та інтерфейсних фононів від аксіального квазіімпульсу $q$ при фіксованих товщинах нанотрубки $h=7 a$ і шару-бар'єру $\Delta=4 a$ та різних значеннях радіуса внутрішньої дротини $\rho_{0}$

$\left.+\left.\sum_{p=1}^{2}\left[A_{p} I_{m}(q \rho)+B_{p} K_{m}(q \rho)\right]\right|_{\rho_{p-1} \leq \rho \leq \rho_{p}}\right]$

Отриманий гамільтоніан (26) є базовим при дослідженнях перенормування електронного енергетичного спектра взаємодією з обмеженими та інтерфейсними фононами. Його перевага в тому, що в отриманій формі для нього цілком застосовні методи квантової теорії поля, зокрема, метод функцій Гріна та діаграмна техніка Фейнмана. Це дозволяє вивчати випадки зі всіма можливими силами зв'язку квазічастинок $з$ фононами складної циліндричної нанотрубки.

\section{4. Аналіз та обговорення результатів}

Залежність електронного та екситонного спектрів від геометричних параметрів складної циліндричної напівпровідникової нанотрубки детально вивчалася нами у роботі [12]. Тому в цій роботі обмежимось аналізом фононних спектрів та потенціалів поля поляризації у циліндричній нанотрубці на основі напівпровідників GaAs (середовище “0”) та $\mathrm{Al}_{0,4} \mathrm{Ga}_{0,6} \mathrm{As}$ (середовище "1"), матеріальні параметри яких такі. Енергії поздовжних та поперечних оптичних фононів середовищ " 0 " та " 1 ": $\Omega_{L 0}=35 \mathrm{меB}, \Omega_{T 0}=32,2$ меВ, $\Omega_{L 1}=39,4$ меВ, $\Omega_{T 1}=35,95$ меВ; сталі гратки $a=a_{0} \approx a_{1}=5,65 \AA$; діелектричні проникності: $\varepsilon_{\infty 0}=10,85, \varepsilon_{\infty 1}=9,8$.

Результати розрахунку фононного спектра у наносистемі, що досліджується, при фіксованих (типових для експериментально створених наносистем [8]) товщинах нанотрубки $h=7 a$ і шару-бар'єру $\triangle=4 a$ та
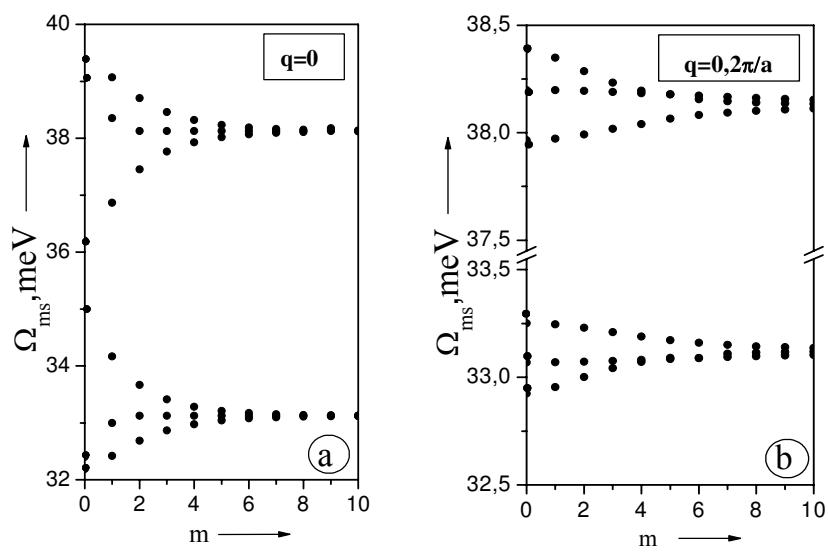

Рис. 3. Залежність енергії $\left(\Omega_{m s}\right)$ інтерфейсних фононів від $m$ при $q=0(a)$ та $q=0,2 \pi / a(b)$ при $\rho_{0}=5 a, \Delta=4 a, h=7 a$

різних значеннях радіуса $\left(\rho_{0}\right)$ внутрішньої дротини наведено на рис. 2. 3 нього добре видно властивості цього спектра і його еволюція зі зміною геометричних параметрів наносистеми.

3 рис. 2, a видно, що за відсутності внутрішнього середовища $\left(\rho_{0}=0\right)$ фононний спектр містить бездисперсійні енергії обмежених фононів $\left(\Omega_{L 0}, \Omega_{L 1}\right)$ і чотири групи з безмежною кількістю гілок $(m=$ $0,1, \ldots, \infty)$ енергій інтерфейсних фононів $\left(\Omega_{m s}(q)\right)$ зі слабкою дисперсією по $q$. На рис. 2 наведено лише $\Omega_{m=0,1 s}(q)$, а значення $\Omega_{m s}$ при інших величинах $m$ наведені на рис. $3, a, b$ при $\rho_{0}=5 a, q=0$ та $q=0,2 \pi / a$ відповідно.

3 рис. 2,a видно, що при $m=0$ та $m=1$ дві гілки I-фононів мають додатну, а дві - від'ємну диспер- 

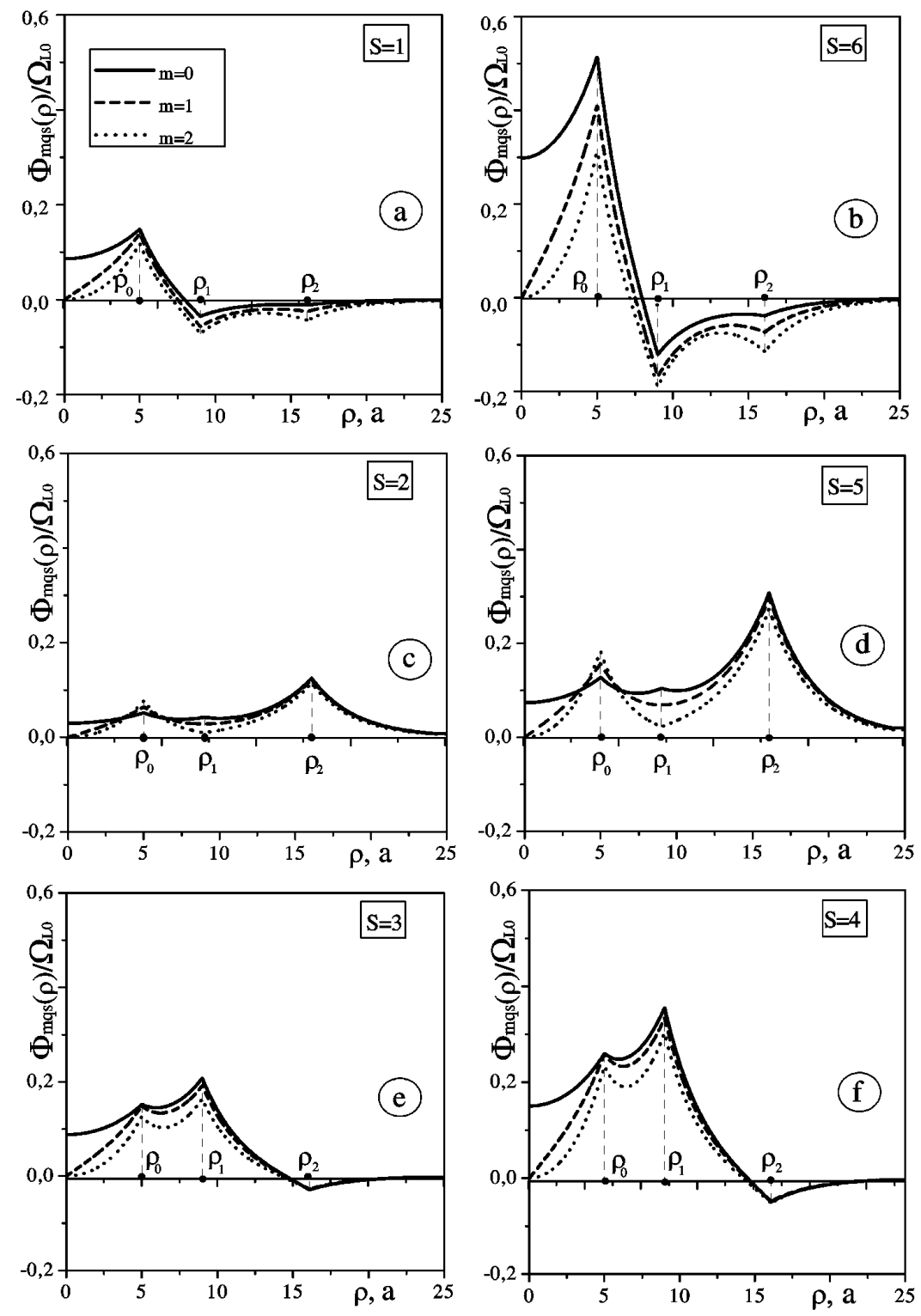

Рис. 4. Залежність потенціалу $\Phi_{m q s}(\rho)$ від змінної $\rho$ при $q=0,2 \pi / a, \rho_{0}=5 a, h=7 a, \Delta=4 a$

сію. Енергії кожної з груп І-фононів знаходяться у межах між $\Omega_{L 1}$ та $\Omega_{T 1}-$ верхні і між $\Omega_{L 0}$ та $\Omega_{T 0}-$ нижні.

Якщо ж циліндрична нанотрубка має внутрішній радіус $\rho_{0} \neq 0$ (рис. $2, b, c, d$ ), то у спектрі інтерфейсних фононів з'являються ще дві групи гілок: у низькоенергетичній області $\Omega_{m 2}(q)$ - група з додатною дисперсією, а в області вищих енергій $-\Omega_{m 5}(q)$ - група 3 від'ємною дисперсією.

Фізичною причиною наявності чотирьох при $\rho_{0}=$ 0 , та шести при $\rho_{0} \neq 0$ груп гілок інтерфейсних фононів $є$ існування у наносистемі двох $\left(\rho_{0}=0\right)$ чи трьох $\left(\rho_{0} \neq 0\right)$ поверхонь розділу напівпровідникових середовищ $\mathrm{GaAs} / \mathrm{Al}_{0,4} \mathrm{Ga}_{0,6} \mathrm{As}$ (рис. 1).

3 рис. 2,b,c,d видно, що при фіксованій ширині трубки дисперсія інтерфейсних фононів лише при малих величинах $q$ чутлива до зміни $\rho_{0}$. У області $q \geq 0,1 \pi / a$ при всіх значеннях $\rho_{0}$ енергії інтерфейсних фононів практично не змінюються.

3 рис. 3, $a, b$ видно, що дисперсія по $m$ усіх груп інтерфейсних фононів також незначна і подібна до дисперсії по q. Це цілком зрозуміло, оскільки при $\rho_{0} \rightarrow \infty$ саме квантове число $m$ переходить у квазіімпульс, перпендикулярний до напрямку $q$, адже в 
такому випадку циліндрична нанотрубка переходить у складну плоску наногетеросистему з геометричними параметрами $\triangle$ та $h$.

На рис. 4, $a-f$ зображено залежність потенціалу $\left(\Phi_{m q s}(\rho)\right)$ в одиницях $\Omega_{L 0}$ від змінної $\rho$ при $q=$ $0,2 \pi / a, \rho_{0}=5 a, h=7 a, \Delta=4 a$ та різних значеннях магнітного квантового числа $m=0,1,2$ для шести гілок інтерфейсних коливань, пронумерованих індексом $s$ на рис. 2,c.

Зі всіх рисунків видно, що незалежно від номера $(s)$ гілки, потенціальна енергія інтерфейсних фононів немонотонно залежить від $\rho$, досягаючи екстремальних значень на межах поділу напівпровідникових середовищ, що утворюють складну нанотрубку. 3 рис. $4, a-f$ видно, що серед цих шести графіків можна попарно виділити ті, на яких залежність потенціалу $\Phi_{m q s}(\rho)$ якісно однакова у всьому інтервалі зміни $\rho$. Зокрема, рис. 4, $a$ відповідає інтерфейсному фонону з енергією $\Omega_{m 1}$ і додатною дисперсією за $q$, а рис. $4, b$ - інтерфейсному фонону з енергією $\Omega_{m 6}$ і від'ємною дисперсією за $q$. Максимальне значення потенціалу для цих коливань досягається на межі $\rho=\rho_{0}$.

Аналогічні пари можна виділити для потенціалів 3 максимальним значенням на межі $\rho=\rho_{2} 3$ відповідними енергіями $\Omega_{m 2}$ (додатна дисперсія) і $\Omega_{m 5}$ (від'ємна дисперсія) (рис. $4, c, d)$ та потенціалів 3 максимальним значенням на межі $\rho=\rho_{1}$ з енергіями $\Omega_{m 3}$ (від'ємна дисперсія) і $\Omega_{m 4}$ (додатна дисперсія) (рис. $4, e, f)$. Абсолютне значення потенціалу в кожній парі при довільних $\rho$ більше там, де більша енергія відповідного інтерфейсного фонона $\Omega_{m s}$.

Для кожної із гілок $(s=1-6)$ потенціал інтерфейсних фононів при $m=0$ відмінний від нуля навіть при $\rho=0$. Однак для всіх інших $m$ потенціал такий, що $\Phi_{m \neq 0 q s}(0)=0$.

Нарешті зауважимо, що оскільки потенціал поля інтерфейсних фононів максимальний на гетерограницях і швидко спадає по мірі віддалення від межі поділу між напівпровідниковими середовищами, то перенормування електронного спектра цими фононами буде суттєвим лише у надтонких нанотрубках, у яких максимум квадрата модуля електронної хвильової функції також локалізований поблизу інтерфейcy.

\section{5. Висновки}

У моделі ефективних мас для електрона та діелектричного континууму для фононів розвинуто теорію електрон-фононної взаємодії у складній циліндричній напівпровідниковій нанотрубці. Одержано аналітичні вирази для гамільтоніанів взаємодії електрона з обмеженими та інтерфейсними фононами у зображенні вторинного квантування за електронними і фононними змінними.

Встановлено, що у складній нанотрубці є дві бездисперсійні гілки обмежених та шість гілок інтерфейсних фононів зі слабкою дисперсією за магнітним квантовим числом $(m)$ та аксіальним квазіімпульсом $(q)$. При фіксованій ширині трубки дисперсія інтерфейсних фононів лише при малих величинах $q$ чутлива до зміни радіуса внутрішньої дротини $\left(\rho_{0}\right)$.

Показано, що незалежно від номера $(s)$ гілки, потенціал інтерфейсних фононів немонотонно залежить від змінної $\rho$, досягаючи екстремальних значень на межах поділу напівпровідникових середовищ, що утворюють складну нанотрубку.

Автори щиро вдячні доктору фізико-математичних наук, професору М.В. Ткачу за корисні поради при написанні роботи та обговоренні отриманих результатів.

1. K. Suenaga, C. Colliex, N. Demoncy, A. Loiseau, H. Pascard, and F. Willaime, Science 278, 653 (1997).

2. Y. Zhang, K. Suenaga, C. Colliex, and S. Iijima, Science 281, 973 (1998).

3. A.I. Persson, M.W. Larsson, S. Stenstro, B.J. Ohlsson, L. Samuelson, and L.R. Wallenberg, Nature Mater. 3, 677 (2004).

4. В.Г. Дубровский, Г.Э. Цырлин, В.М. Устинов, ФТП 43, 1585 (2009).

5. P. Mohan, J. Motohisa, and T. Fukui, J. Phys. Condens.Matter 88, 013110 (2006).

6. P. Mohan, J. Motohisa, and T. Fukui, Appl. Phys. Lett. 88, 133105 (2006).

7. M. Heigoldt, J. Arbiol, D. Spirkoska, J.M. Rebled, C.S. Conesa-Boj, G. Abstreiter, F. Peiro, J.R. Morantece, and A. Fontcuberta i Morral, J. Mater. Chem. 19, 840 (2009).

8. A. Fontcuberta i Morral, D. Spirkoska, J. Arbiol, M. Heigoldt, J.R. Morante, and G. Abstreiter, Small 4, 899 (2008).

9. X.F. Wang and X.L. Lei, Phys. Rev. B 49, 4780 (1994).

10. N. Tkach, A. Makhanets, and N. Dovganiuk, Phys. Solid State 51, 2529 (2009).

11. M. Tkach, O. Makhanets, M. Dovganiuk, and O. Voitsekhivska, Physica E 41, 1469 (2009).

12. O. Makhanets, N. Tsiupak, and O. Voitsekhivska, in Proceedings of the 12th International Balkan Workshop on Applied Physics, edited by V. Ciupina, H. Alexandru, 
and M. Cirty (Ovidius University Press, Constanta, 2011), p. 94.

13. С.И. Пекар, Исследования по электронной теории кристаллов (ГИТТЛ, Москва, 1951).

14. Л.Д. Ландау, С.И. Пекар, ЖЭТФ 18, 419 (1948).

15. Е. Янке, Ф. Эмде, Ф. Лёш, Специальные функции (Наука, Москва, 1964).

16. М. Строшио, М. Дутта, Фононы в наноструктурах (Физматлит, Москва, 2006).

17. М. Ткач, Квазічастинки у наногетеросистемах. Квантові точки та дроти (Рута, Чернівці, 2003).

ФОНОННЫЕ СПЕКТРЫ И ЭЛЕКТРОН-ФОНОННОЕ ВЗАИМОДЕЙСТВИЕ В СЛОЖНОЙ ЦИЛИНДРИЧЕСКОЙ ПОЛУПРОВОДНИКОВОЙ НАНОТРУБКЕ

\section{А.М. Маханеи, Н.Р. Цюоак, В.И. Гуцул}

Р е з ю м е

В модели эффективных масс для электрона и диэлектрического континуума для фононов развита теория электронфононного взаимодействия в сложной цилиндрической полупроводниковой нанотрубке. Получены аналитические выражения для гамильтонианов взаимодействия электрона с ограниченными и интерфейсными фононами в представлении вторичного квантования по электронным и фононным переменным. Исследованы зависимости фононных энергий и потенциала поля поляризации интерфейсных фононов от аксиального квазиимпульса и геометрических параметров сложной нанотрубки на основе полупроводников $\mathrm{GaAs}$ и $\mathrm{Al}_{0,4} \mathrm{Ga}_{0,6} \mathrm{As}$.

\section{PHONON SPECTRA AND ELECTRON-PHONON INTERACTION IN A COMBINED CYLINDRICAL SEMICONDUCTOR NANOTUBE}

O.M. Makhanets, N.R. Tsiupak, V.I. Gutsul

Yu. Fedkovych Chernivitsi National University (2, Kotsyubynskyi Str., Chernivtsi 58012, Ukraine; e-mail:ktf@chnu.edu.ua)

$\mathrm{S} \mathrm{u} \mathrm{m} \mathrm{m} \mathrm{a} \mathrm{r} \mathrm{y}$

A theory of electron-phonon interaction in a combined cylindrical semiconductor nanotube has been developed in the framework of effective mass model for electrons and dielectric continuum one for phonons. Analytical expressions for Hamiltonians of electron interaction with confined and interface phonons have been derived in the secondary quantization representation for electron and phonon variables. Dependences of phonon energies and interface phonon polarization field potential on the axial quasi-momentum and the geometrical parameters of combined nanotube fabricated on the basis of $\mathrm{GaAs}$ and $\mathrm{Al}_{0.4} \mathrm{Ga}_{0.6}$ As semiconductors have been studied. 